\title{
The effect of dimple error on the horizontal launch angle and side spin of the golf ball during putting
}

Richardson, Ashley K., Mitchel, Andrew C. S. and Hughes, Gerwyn 2016

This is the accepted manuscript of an article published by Taylor \& Francis in the Journal of Sports Sciences on 16 March 2016 available online: http://dx.doi.org/10.1080/02640414.2016.1161213 
1 The effect of dimple error on the horizontal launch angle and side spin

2 of the golf ball during putting

4 Abstract

5 This study aimed to examine the effect of the impact point on the golf ball on

6 the horizontal launch angle and side spin during putting with a mechanical

7 putting arm and human participants. Putts of $3.2 \mathrm{~m}$ were completed with a

8 mechanical putting arm (four putter-ball combinations, total of 160 trials) and

9 human participants (two putter-ball combinations, total of 337 trials). The

10 centre of the dimple pattern (centroid) was located and the following

11 variables were measured; distance and angle of the impact point from the

12 centroid and surface area of the impact zone. Multiple regression analysis

13 was conducted to identify whether impact variables had significant

14 associations with ball roll variables; horizontal launch angle and side spin.

15 Significant associations were identified between impact variables and

16 horizontal launch angle with the mechanical putting arm but this was not

17 replicated with human participants. The variability caused by 'dimple error'

18 was minimal with the mechanical putting arm and not evident with human

19 participants. Differences between the mechanical putting arm and human

20 participants may be due to the way impulse is imparted on the ball. Therefore

21 it is concluded that variability of impact point on the golf ball has a minimal

22 effect on putting performance.

23 Words: 199

24 


\section{Introduction}

27 Based on Professional Golf Association (PGA) Tour statistics during 2014,

28 the putting stroke accounted for approximately $40 \%$ of all strokes during 29 tournament rounds (PGA Tour, 2015a; 2015b). This is in accordance with

30 Dorsel \& Rotunda (2001) and Alexander and Kern (2005), who identified that

31 putting average was a key contributor to determining earnings on the PGA

32 Tour. A number of factors are considered to influence the success rate of a

33 golf putt, namely, green reading, aim, stroke and ball roll (Karlsen, Smith \&

34 Nilsson, 2008). Regarding the putting stroke, Pelz (2000) considered two

35 variables that account for direction variability, face angle at impact (83\%) and

36 the putter path (17\%). Karlsen et al. (2008) accounted $80 \%$ of direction

37 consistency to face angle at impact $\left(0.50^{\circ}\right.$ effective variability), $17 \%$ to putter

38 path $\left(0.18^{\circ}\right.$ effective variability $)$ and $3 \%$ to horizontal impact point on the

39 putter $\left(0.09^{\circ}\right.$ effective variability $)$. One variable that has not been considered

40 at length within the literature considering direction variability is the impact

41 point on the golf ball.

43 Golf balls are designed with dimples to reduce the drag of the golf ball when

44 in flight (Aoki, Nakayama, Hayasida, Yamaguti \& Sugiura, 1998; Goff, 2013).

45 These dimples, however, may also be a detriment to putting performance.

46 Due to the dimples a golf ball is not perfectly spherical with potential for the

47 golf ball to rebound off the putter during impact at an unexpected angle

48 (Cross \& Nathan, 2007). To explain this further, the putter could strike the

49 perimeter of the dimple 'flat' allowing the initial roll of the ball to leave in the

50 intended direction towards the target. Or the putter could strike an edge of a 
51 dimple causing a deflection of direction off the intended target line (Figure 1).

52 Research has acknowledged that dimples do affect the direction variability

53 during a golf putt, however; only limited data is presented through a simple

54 analysis of the distance that putts have rolled off line (Pelz, 2000). The

55 authors of the current study propose that the direction variability away from

56 the intended target line accountable to the impact point on the golf is termed

57 dimple error. In addition to the horizontal launch angle another variable

58 relatively unexplored is the side spin imparted on the golf ball. Hurrion and

59 Mackay (2012) have identified that side spin imparted on the ball (> $20 \mathrm{rpm}$ )

60 has potential to cause the ball travelling off the intended target line; this is

61 accountable to resultant angle differences between the putter path and face

62 angle. Therefore, could potentially be a contributing factor to missed putts

63 along with the horizontal launch angle.

65 FIGURE ONE ABOUT HERE

67 Dimple error will be more prominent when executing shorter golf putts, this is

68 due to greater compression of the golf ball during longer golf putts (Pelz,

69 2000). Dimple error is likely to have an inverse relationship with the

70 compression of the golf ball, therefore may only be applicable during a

71 shorter golf putt. Cross (2006) demonstrated in a non-golf environment that

72 the golf ball can deflect off at a random angle, whereas a ball bearing

73 bounced symmetrically and vertically. It was suggested that the dimples

74 caused the random deflection (Cross, 2006). This was tested dropping the

75 balls onto a marble surface from a height of $80 \mathrm{~cm}$. There are limitations 
76 associated with this experiment, as in a golf situation the ball is the stationary

77 object and the club the moving object. Therefore, Cross (2006) does not

78 accurately replicate the putter-ball impact as it occurs on the putting green.

79 With the initial direction of the golf ball predominantly being determined by

80 the putter face angle (Karlsen et al., 2008), the random deflection will be less

81 significant than observed by Cross (2006). Therefore research is needed to

82 determine whether this mechanism is apparent to any extent in a golf

83 environment.

85 Different types of putter face have previously been compared (Hurrion \& 86 Hurrion, 2002; Brouillette, 2010), however, putting remains to date an under

87 researched area. Additionally, focus has predominantly been on the effect of

88 topspin imparted on the golf ball rather than the initial direction of the golf

89 ball, which is clearly an important factor of whether a putt is successful or

90 not. Contrasting results were however observed, whereby Hurrion and

91 Hurrion (2002) observed improved topspin in trials completed with a grooved

92 faced putter whereas Brouillette (2010) did not report improved topspin

93 between a grooved faced and traditional faced putter. This provides rationale

94 to test putters with different face inserts however, neither considered the

95 effect of the variability of the impact point on the golf ball.

97 The aim of this study was to investigate the effects of impact point on the golf

98 ball on the resulting horizontal launch angle (initial direction) and side spin of

99 the golf ball. This will be investigated using a mechanical putting arm and

100 human participants. It was hypothesised that significant associations 
101 between the variance of the kinematic variables (horizontal launch angle and

102 side spin) and the impact point on the golf ball would exist.

103

104 Methods

105

106 Participants

107 A total of 22 right handed golfers participated in the study (age $42 \pm 12$

108 years; handicap $13.6 \pm 7.4$ (handicap range $0-24$ ); height $1.76 \pm 0.21$

109 metres; mass $88.6 \pm 23.8 \mathrm{~kg}$ ). All golfers were free of musculoskeletal injury

110 for the previous three months and played a minimum of once a week. During

111 testing participants wore their own personal golfing attire and golf shoes. All

112 participants provided written informed consent and the study was approved

113 by the institutional ethics committee of University of Hertfordshire.

115 Experimental set-up

116 Two testing sessions were completed to establish the association between

117 the impact point on the golf ball and the initial direction of the golf putt.

118 Firstly, with a mechanical putting arm where the putting stroke parameters

119 putter face angle, putter path and impact point on the putter were 120 standardised and secondly with human participants to determine whether

121 results are applicable in a practical setting.

123 A mechanical putting arm was setup to reproduce a putt of 3.2 metres on an

124 artificial putting surface registering 12 on the stimpmeter (The United States

125 Golf Association, Far Hills, NJ, USA). A square to square swing path was 
126 selected to ensure a square club face at impact, referring to a single

127 horizontal axis that was perpendicular to the putting line. Human participants

128 completed a level straight 3.2 metre putt on a Huxley Golf (Huxley Golf,

129 Hampshire, UK) artificial putting green (3.66 x 4.27 metres) registering 11 on

130 the stimpmeter.

131

132 The putters used for both testing sessions were the grooved faced $\mathrm{GEL}^{\circledR}$

133 Vicis (GEL GOLF., Wan Chai, Hong Kong) and traditional faced Odyssey

134 White Hot \#3 (Callaway Golf Europe Ltd., Surrey, UK). Both putters had a

135 standardised $69^{\circ}$ lie and $2.5^{\circ}$ loft. Srixon Z-STAR golf balls (Srixon Sports

136 Europe LTD., Hampshire, UK) and Titleist Pro V1 golf balls (Acushnet

137 Europe Ltd., Cambridgeshire, UK) were aligned using two Superline 2D line

138 lasers (Property Perspective Ltd., Warwick, UK). Ball placement during

139 testing with the mechanical putting arm was standardised by placing one

140 laser directly behind the golf ball and the second $90^{\circ}$ perpendicular to the

141 path of the golf ball. Dimples were then orientated by ensuring the visual aid

142 printed on the golf ball was intersected with both lasers. Participants testing

143 were completed with only the Srixon golf ball; these were aligned in the

144 manner as the mechanical putting arm to ensure the same placement of the

145 golf ball across trials.

146

147 To record the horizontal launch angle (degree to which the ball deviates $\left(^{\circ}\right.$ )

148 from the original putting line) and side spin (the amount of side spin (rpm)

149 placed on the ball at impact) of the golf ball, a Quintic (Quintic Consultancy

150 Ltd., Coventry, UK) high speed camera (UI-5220RE) sampling at $220 \mathrm{~Hz}$ was 
151 positioned perpendicular to the putting line. The Quintic Ball Roll v2.4 launch

152 monitor software was used to analyse the recorded videos. A Quintic GigE

153 high speed camera sampling at $220 \mathrm{~Hz}$ was positioned vertically $(1.8 \mathrm{~m}$

154 above putting surface) to validate the horizontal launch angle values during

155 testing with the mechanical putting arm. A Canon (Canon Europe Ltd, Tokyo,

156 Japan) EOS $1000 d$ camera was placed on a tripod away from the putting line

157 where it did not disturb the view of the participant during the trial or impede

158 the mechanical putting arm. This camera took images of the impact point of

159 the golf ball post trial.

160

161 Procedure

162 During testing with the mechanical putting arm, each putter was held

163 securely within a clamping mechanism. A putting arm block was placed at an

164 appropriate distance behind the golf putter to produce the desired length of

165 putt, and the putting arm was released by deactivating an electromagnet.

166 Before each trial a thin layer of pigmented emollient was applied to the putter

167 face and smoothed. The golf ball was then aligned using the Superline lasers

168 dissecting the ball into four equal sections, ensuring the same position for

169 each trial. Forty trials were completed with each putter-ball combination

170 (GEL ${ }^{\circledR}$-Srixon, GEL ${ }^{\circledR}$-Titleist, Odyssey-Srixon and Odyssey-Titleist). Trials

171 were filmed with the Quintic Ball Roll software. Additionally, after each trial a

172 picture was taken of the golf ball placed in a pre identified position $(50 \mathrm{~cm}$

173 away from the camera) (identifying the pigmented emollient imprint on the

174 ball) with the Canon EOS 1000d camera. 
176 During testing with human participants, an initial period of habituation was

177 allowed with the first putter that had been randomly selected. This

178 habituation period was repeated for the second putter when swapped during

179 the protocol. During both habituation periods the participant was informed of

180 the initial ball velocity threshold $(2.10-2.28 \mathrm{~m} / \mathrm{s})$. This was to ensure a

181 similar pace of putt between participants and during habituation subjects

182 found it relatively easy to satisfy this criteria. After habituation, the

183 investigator lined up the putt with the Superline lasers. This process was

184 completed until six successful (holed) putts had been completed with each

185 putter; however, missed putts were included within the analysis. Six

186 successful putts were selected as criteria, due to procedural limitations (time

187 of analysis) whilst still giving a suitable number of trials.

188

189 Data Processing

190 Using Adobe Photoshop CS5 (Adobe Systems Incorporated., CA, USA) a 0,

1910 coordinate was identified as the centre of the dimple pattern. This was

192 defined as the centroid location (Figure 2; centre of the pentagon and where

193 lines $A$ ) and B) join). All impact measurements were then made from this 0,0

194 coordinate. For the Srixon golf ball an equilateral triangle drawing was

195 overlaid on the image identifying the centroid location of three dimples. The

196 Titleist ball had two different sized dimples; therefore a pentagon drawing

197 was placed on the image identifying the centroid location of one smaller

198 dimple surrounded by five larger dimples. 
200 The contact made between the putter and ball during the impact was termed 201 the impact zone. To determine the length $(\mathrm{mm})$ and angle (direction of

202 impact from the centroid location $\left.\left({ }^{\circ}\right)\right)$ the centre of the impact zone had to be

203 calculated. To complete this a polygon was drawn at the outermost edges of

204 the impact zone and intersected from the four corners, giving a centre point

205 (Figure 2; end of line A) away from centroid location). From this, differences

206 in length (Figure 2; of line A)) and angle (Figure 2; angle between line A) and

207 B) between the standardised centroid location and impact point were

208 measured. The surface area of the impact zone (area of contact between the

209 putter and ball) was measured using ImageJ (National Institutes of Health,

210 Bethesda, Maryland, USA). Using the polygon selection tool the edges of the

211 impact zone were connected giving an output $\left(\mathrm{mm}^{2}\right)$ of surface area (Figure

212 2; area of grey shading within white outline). A more detailed explanation of

213 how the data were processed is presented in Richardson, Mitchell and

214 Hughes (2015).

216 FIGURE TWO ABOUT HERE

\section{Data Analysis}

219 The impact variables measured were the length of the impact point from the

220 centroid location, angle of the impact point from the centroid location and

221 surface area of the impact zone, which was used for the multiple regression

222 analysis. The dependent variables were the horizontal launch angle (the

223 degree to which the ball deviates from the original putting line) measured in

224 degrees and side spin (the amount of cut or hook spin (rpm) placed on the 
225 ball during impact). Data were exported to statistical software packages

226 SPSS v21 (SPSS Inc, Chicago, USA) for analysis.

227

228 The linearity of the data was first assessed by examining residual plots 229 (standardised residuals as a function of standardised predicted values) 230 (Pedhazur, 1997). Then the data were analysed for normality by assessing 231 histogram and box-plot graphs, kurtosis and skewness values. If kurtosis or

232 skewness values were found to be $> \pm 1$, the data set was identified as highly 233 skewed or kurtosed, between \pm 0.5 and \pm 1 the data set was identified as 234 moderately skewed or kurtosed, and between 0 and \pm 0.5 the data was 235 considered to be approximately symmetrical (Bulmer, 1979) and therefore 236 displaying normality. Any data sets that were found to be highly skewed or 237 displaying high kurtosis was transformed logarithmically (log) in order to 238 increase uniformity to a normal distribution curve (Atkinson \& Nevill, 1998; 239 Hopkins, Marshall, Batterham \& Hanin, 2009). The only data set that 240 required log transforming was the Odyssey-Titleist group (tested with the 241 mechanical putting arm). Descriptive data of the log-transformed data sets 242 are presented in their absolute form. Box-plots were used to identify outliers 243 within the data set; if an outlier was identified for one impact variable the 244 entire trial was removed from analysis.

246 Bivariate analysis was undertaken for the independent and dependent 247 variables to ensure multicollinearity was avoided. Correlations were 248 identified as very high if $r \geq 0.90$ (Ntoumanis, 2001). Additionaly, collinearity 249 diagnostics, variance inflation factor (VIF) and the tolerance statistic were 
250 used to assess multicollinearity. A VIF greater than 10, was identified as a 251 cause of concern (Bowerman \& O'Connell, 1990; Myers, 1990) and a 252 tolerance below 0.2 indicated a problem (Menard, 1995). Multiple regression 253 analysis was then completed. The independent variables length from the 254 centroid location ( $\mathrm{mm}$ ), angle from the centroid location $\left(^{\circ}\right)$ and surface area $255\left(\mathrm{~mm}^{2}\right)$ were the predictors used to assess whether the impact point on the 256 golf ball effected side spin and horizontal launch angle. Level of significance 257 was set at $\alpha<0.05$.

259 Results

260 Horizontal Launch Angle with the mechanical putting arm

261 Mean and standard deviations for the independent variables length, angle

262 and surface area are presented in Table 1. The multiple regression model 263 was found to be a significant predictor of horizontal launch angle for the $264 \operatorname{GEL}^{\circledR}{ }^{\circledR}$-Titleist $(p=0.001), \mathrm{GEL}^{\circledR}$-Srixon $(p=0.001)$ and Odyssey-Srixon $(p=$ 2650.03 ) groups, but not for the Odyssey-Titleist group $(p=0.18)$ (Table 2). The 266 impact variables accounted for $34 \%$ of the variability of horizontal launch

267 angle for the $\mathrm{GEL}^{\circledR}{ }^{\circledR}$-Titleist group, 44\% for the GEL ${ }^{\circledR}$-Srixon group and $21 \%$ 268 of the variability for the Odyssey-Srixon group. The range of results 269 observed for the horizontal launch angle were -1.00 to $0.71^{\circ}$.

271 TABLE ONE ABOUT HERE

272

273 TABLE TWO ABOUT HERE 


\section{Horizontal Launch Angle with human participants}

276 The multiple regression model was not a significant predictor of horizontal

277 launch angle for either the $\operatorname{GEL}^{\circledR}$-Srixon $(p=0.52)$ or Odyssey-Srixon $(p=$

278 0.49) combinations (Table 3). Although not significant, the variability

279 accountable to the impact (predictor) variables would have been negligible at $2802 \%\left(0.03^{\circ}\right)$ and $1 \%\left(0.02^{\circ}\right)$ for the $\mathrm{GEL}^{\circledR}{ }^{\circledR}$-Srixon and Odyssey-Srixon groups

281 respectively. Figure 3 demonstrates the different variance in the impact

282 points on the golf ball between the mechanical putting arm and human

283 participants, where increased variance is observed in the latter.

284

285 TABLE TWO ABOUT HERE

286

287 Side spin with the mechanical putting arm

288 Significant association was found between side spin with all predictors 289 (length, angle and surface area) coupled for the Odyssey-Srixon combination $290(p=0.04)$. The impact variables accounted for $20 \%(2.8 \mathrm{rpm})$ of the variation 291 within this group (Table 4). There were no significant associations between 292 the impact variables and kinematic variables for the other three putter-ball 293 combinations.

295 TABLE THREE ABOUT HERE

297 Side spin with human participants

298 The multiple regression model was found to be a significant predictor of side

299 spin (Table 5) for the $\mathrm{GEL}^{\circledR}$ putter $(p=0.04)$ but not for the Odyssey putter ( $p$ 
$300=0.93)$. The impact variables accounted for $6 \%$ of variation observed in side

301 spin (1.54 rpm) for the $\mathrm{GEL}^{\circledR}$ putter

302

303 TABLE FOUR ABOUT HERE

304

305 Discussion

306 This is the first study to have measured and analysed the effects of the

307 impact point on the golf ball on subsequent ball roll kinematics. It was

308 hypothesised that significant associations would exist between the variance

309 of the horizontal launch angle and impact point variables. This were

310 accepted with the mechanical putting arm but rejected with human

311 participants. Regarding side spin, the hypothesis can be rejected with the

312 mechanical putting arm and partially accepted with human participants. The

313 variance of the horizontal launch angle with the mechanical putting arm was

314 minimal. This however can be attributed to dimple error during putting, with

315 the dimple orientation, putter face angle and path being controlled during the

316 experiment. With no significant associations identified with human

317 participants, dimple error is unlikely to have any implications on putting

318 performance. This is also apparent with side spin where only $20 \%$ of

319 variance was accountable for one putter-ball combination.

320

321 Pelz (2000) states that the larger the golf ball dimples, the more likely contact

322 made on the edge of a dimple will affect the horizontal launch angle, as each

323 dimple is covering a larger surface area. However, the smaller the dimple,

324 the increased number of dimples there will be covering the ball, therefore 
325 increasing the chance of making contact with the edge of a dimple. Although

326 a golf ball with larger dimples has less chance of contact being made to a

327 dimple edge, the horizontal deviation caused by impact may increase. This

328 was not observed in the current study. Dimple circumferences of $12.4 \mathrm{~mm}$

329 (Titleist Pro V1) and $12.9 \mathrm{~mm}$ (Srixon Z-STAR) were measured, indicating

330 more variability was expected for the Srixon golf ball. More variance was

331 however observed for the Titleist ball $\left(\mathrm{GEL}^{\circledR}-\right.$ Titleist $=0.15^{\circ}$, Odyssey-Titleist

$\left.332=0.06^{\circ}\right)$ in comparison to the Srixon $\left(\mathrm{GEL}^{\circledR}-\right.$ Srixon $=0.13^{\circ}$, Odyssey-Srixon

$\left.333=0.04^{\circ}\right)$. Differences are marginal between each group, however, based on

334 these results, it seems the different putters used in testing had more

335 influence on the horizontal launch angle (and therefore success rate of a

336 putt), rather than the impact point on the golf ball when using a mechanical

337 putting arm with standardised stroke kinematics. This is based on the

338 differences in variance of the horizontal launch angle being observed

339 between putters rather than golf balls.

341 During testing with the mechanical putting arm, all 160 trials would have

342 resulted in a successful putt (holed), even with the variation observed with

343 the horizontal launch angle and side spin. Therefore, the variation

344 accountable to the impact variables can be considered negligible for a

345 simulated putt. This is in accordance with Karlsen et al. (2008) who stated

346 that variables of the putting stroke including the putter face angle, putter path

347 and horizontal impact point on the putter face (standardised in mechanical

348 putting arm protocol) only have a minor influence on the direction

349 consistency in golf putting in elite players. Karlsen et al. (2008) accounted 
$3503 \%$ of direction consistency to the impact point on the putter face. This

351 variability may not just be due to the variability on the putter face but also the

352 impact point on the golf ball, as demonstrated by the results in the current

353 study with the mechanical putting arm. This minor variation will not affect

354 success rate from 12 feet. As Hurrion and Mackay (2012) state that for a putt

355 to be successful from this distance a horizontal launch angle threshold of

$3560.75^{\circ}$ would need to be exceeded. Results in the current study were within

357 this threshold whilst using the mechanical putting arm.

359 Along with the mechanical putting arm, dimple error can additionally be 360 considered inconsequential for golfers, with no significant associations 361 identified (Table 3). Differences in significant associations between the 362 mechanical putting arm and human participants may be due to human 363 participants' differences in stroke kinematics such as the face angle and 364 putter path trial to trial as previously identified within the literature (Karlsen et 365 al., 2008; Pelz, 2000). Whilst no measurements were made of the putter face 366 angle and putter path the authors consider this to be a reasonable 367 assumption. The magnitude of the effects of the variation in putter face angle 368 and putter path may render the effects of dimple error statistically negligible.

369 For example, if the left hand side of a dimple was struck by the putter, for 370 dimple error to potentially affect the horizontal launch angle the putter face 371 would also have to be slightly open. However, natural variation will occur in 372 clubface angle at impact which may have contributed to the larger variation 373 observed in golfers in comparison to the mechanical putting arm (Figure 3).

374 Additionally, with a large range of handicaps observed in the current study 
375 (handicap: $13.6 \pm 7.4$ ), golfers with a higher handicap will demonstrate a

376 wider range of natural variation in the face angle and putter path. Therefore,

377 these factors will have an increased effect, rendering dimple error even less

378 important regarding putting performance.

379

380 For a putt of 12 feet, Hurrion and Mackay (2012) state a putt with an initial 381 horizontal launch angle of within $0.75^{\circ}$ would be successful which would be

382 produced with a putter face angle of $0.69^{\circ}$ based on the putter face angle 383 determining $92 \%$ of the direction of the putt. Based on results with the 384 mechanical putting arm (Table 2), the addition of dimple error could reduce 385 the chance of a successful putt. However, with results not being reproduced 386 with golfers it can be considered that dimple error is not a problem a golfer 387 should be concerned about, particularly considering the difficulty in 388 controlling for it.

390 No literature to date has explored the initial phase of skid and side spin and 391 has focused on when the ball enters a state of pure rolling (Alessandri, 1995; 392 Hurrion \& Hurrion, 2002; Lorensen \& Yamrom, 1992; Penner, 2002). It has 393 been stated that friction between the ball and the green removes all spin in 394 approximately the first $20 \%$ of the roll (Pelz, 2000), therefore it may be 395 possible that friction between the stationary ball and green contributes 396 towards the side spin initially along with the small amounts of rotation during 397 impact. Potentially explaining a portion of the large variability observed in 398 human participants (Table 5). 
400 The practical implications of this study are that golfers should not be overly

401 concerned with dimple error, as the effects are very small and it would be

402 very difficult to control for. Dimple error has the potential to reduce the

403 success rates of putts by taking a putt over the initial horizontal launch angle

404 'threshold' of a holed putt. Despite being identified as statistically not

405 significant in the current study, dimple error may add to the direction error

406 along with larger contributions of the putter face angle and putter path.

407 However, as this can be considered negligible at most, therefore golfers

408 training and practice focus should remain on factors known to affect the

409 variability of the horizontal launch angle, with particular emphasis on the

410 putter face angle.

\section{Conclusion}

413 Significant associations were identified between the horizontal launch angle

414 and the point of impact on the golf ball when using a mechanical putting arm

415 with standardised parameters. This, however, was not replicated with golfers

416 where no significant associations were identified. The differences may be

417 accountable to the variance across trials of the putter face angle and path

418 with the human participants. The practical implications of this study are that

419 golfers should not be concerned with dimple error during the putting activity

420 and should instead focus on other elements that contribute to a successful

421 golf putt, such as focusing on the putter face angle, which has previously

422 been found to significantly contribute to the direction of a golf putt. 


\section{References}

426 Alessandrini, S. M. (1995). A motivational example for the numerical solution of two-point boundary-value problems. SIAM review, 37(3), 423-427.

428 Alexander, D. L., \& Kern, W. (2005). Drive for show and putt for dough? An 429 analysis of the earnings of PGA Tour golfers. Journal of Sports $430 \quad$ Economics, 6(1), 46-60.

431 Aoki, K., Nakayama, Y., Hayasida, T., Yamaguti, N., \& Sugiura, M. (1998).

432 Flow Characteristics of a Golf Ball Using Visualization Techniques.

433 In: Farrally, M. R., \& Cochran, A. J., editors. Science \& Golf III: 434 Proceedings of the World Scientific Congress of Golf. Human $435 \quad$ Kinetics; pp. 446-456.

436 Atkinson, G., \& Nevill, A. M. (1998). Statistical methods for assessing measurement error (reliability) in variables relevant to sports medicine. Sports Medicine, 26(4), 217-238.

439 Bowerman, B. L., \& O'Connell, R. T. (1990). Linear Statistical Models: An $440 \quad$ Applied Approach. Belmont California: Duxbury Press.

441 Brouillette, M. (2010). Putter features that influence the rolling motion of a golf ball. Procedia Engineering, 2(2), 3223-3229.

443 Bulmer, M. G. (1979). Principles of Statistics. Courier Corporation.

444 Cross, R., \& Nathan, A. M. (2007). Experimental study of the gear effect in 445 ball collisions. American Journal of Physics, 75, 658-664.

446 Cross, R. (2006). Physics of golf. Retrieved Jan 14 2015, from, http://www.physics.usyd.edu.au/ cross/GOLF/GOLF.htm 
448 Debicki, D. B., \& Gribble, P. L. (2004). Inter-joint coupling strategy during adaptation to novel viscous loads in human arm movement. Journal of Neurophysiology, 92(2), 754-765.

451 Dorsel, T. N., \& Rotunda, R. J. (2001). Low scores, top 10 finishes, and big money: An analysis of professional golf association tour statistics and how these relate to overall performance. Perceptual and Motor Skills,

Goff, J. E. (2013). A review of recent research into aerodynamics of sport projectiles. Sports Engineering, 16(3), 137-154.

457 Hirashima, M., Kudo, K., \& Ohtsuki, T. (2003). Utilization and compensation of interaction torques during ball-throwing movements. Journal of Neurophysiology, 89(4), 1784-1796.

Hopkins, W. G., Marshall, S. W., Batterham, A. M., \& Hanin, J. (2009).

463 Hurrion, P. D., \& Hurrion, R. D. (2002). An investigation into the effect of the roll of a golf ball using the C-groove putter. In: Thain, E., editor. Science and Golf IV: Proceedings of the World Scientific Congress of Golf. London: Routledge; pp. 531-538.

467 Hurrion, P. D., \& MacKay, J. (2012). A Rolling Brief: Golf International, 111, $468 \quad 107-111$.

469 Karlsen, J., Smith, G., \& Nilsson, J. (2008). The stroke has only a minor $470 \quad$ influence on direction consistency in golf putting among elite players. $471 \quad$ Journal of Sports Sciences, 26(3), 243-250. 
472 Lorensen, W. E., \& Yamrom, B. (1992). Golf green visualization. IEEE $473 \quad$ Computer Graphics and Applications, 12(4), 35-44.

474 Menard, S. (1995). Applied logistic regression analysis. Sage University $475 \quad$ Paper Series on Quantitative Applications in the Social Sciences, 07476 106. Thousand Oaks, California: Sage.

477 Myers, R. (1990). Classical and Modern Regression with Applications. $478 \quad$ Boston: Duxbury Press.

479 Ntoumanis, N. (2001). A step-by-step guide to SPSS for sport and exercise $480 \quad$ studies. London: Routledge.

481 Osis, S. T., \& Stefanyshyn, D. J. (2012). Golf players exhibit changes to grip 482 speed parameters during club release in response to changes in club stiffness. Human Movement Science, 31(1), 91-100.

484 Pedhazur, E. J. (1997). Multiple regression in behavioral research: 485 Explanation and prediction. Belmont, California: Wadsworth Publishing Company.

487 Pelz, D. T. (2000). Dave Pelz's Putting Bible. New York: Random House.

488 Penner, A. R. (2002). The physics of putting. Canadian Journal of Physics, 489 80(3), 83-96.

490 PGA Tour (2015a). 2014 PGA TOUR scoring average (actual). Retrieved 491 June 28 2015, from, http://www.pgatour.com/stats/stat.120.2014.html. 492 PGA Tour (2015b). 2014 PGA TOUR putts per round. Retrieved June 28 493 2015, from, http://www.pgatour.com/stats/stat.119.html

494 Richardson, A. K., Mitchell, A. C., \& Hughes, G. (2015). Reliability of an 495 experimental method to analyse the impact point on a golf ball during 496 putting. Sports Biomechanics, (ahead-of-print), 1-10. 
497 Tables

498 Table 1. Mean \pm SD for the independent variables used in regression $(H P)$

499 refers to testing completed by human participants.

\begin{tabular}{cccc}
\hline & Length: Mean \pm & Angle: Mean \pm & Surface Area: \\
& SD & SD & Mean \pm SD \\
& $(\mathrm{mm})$ & $\left({ }^{\circ}\right)$ & $\left(\mathrm{mm}^{2}\right)$ \\
\hline GEL $^{\circledR}$-Titleist & $2.82 \pm 0.85$ & $140.94 \pm 12.38$ & $18.88 \pm 4.34$ \\
GEL ${ }^{\circledR}$-Srixon & $1.49 \pm 0.59$ & $122.60 \pm 41.06$ & $21.36 \pm 4.04$ \\
Odyssey-Titleist & $3.09 \pm 0.74$ & $145.37 \pm 11.57$ & $21.83 \pm 4.63$ \\
Odyssey-Srixon & $1.59 \pm 0.70$ & $131.77 \pm 54.73$ & $23.95 \pm 4.72$ \\
GEL ${ }^{\circledR}$-Srixon & & & \\
$($ HP) & $4.54 \pm 2.45$ & $152.87 \pm 110.41$ & $24.86 \pm 4.78$
\end{tabular}

Odyssey-Srixon

$(\mathrm{HP})$

$4.46 \pm 2.25 \quad 119.53 \pm 82.04 \quad 26.71 \pm 4.98$

500

501

502

503

504

505

506

507

508

509 
510 Table 2. Linear regression model, between predictors and the kinematic

511 variable horizontal launch angle, $R^{2}$ ( \pm standard error normalised as a

512 percentage of the mean (SE\%)) and standardised coefficients.

\begin{tabular}{|c|c|c|c|c|}
\hline & $\begin{array}{l}\mathrm{GEL}^{\left({ }_{-}\right.} \\
\text {Titleist }\end{array}$ & $\begin{array}{l}\mathrm{GEL}^{\circledR}{ }_{-}^{-} \\
\text {Srixon }\end{array}$ & $\begin{array}{l}\text { Odyssey- } \\
\text { Titleist }\end{array}$ & $\begin{array}{l}\text { Odyssey- } \\
\text { Srixon }\end{array}$ \\
\hline Mean \pm SD & & & & \\
\hline $\begin{array}{l}\text { (Right }(+), \\
\left.\text { Left }(-),{ }^{\circ}\right)\end{array}$ & $0.47 \pm 0.43$ & $0.31 \pm 0.30$ & $0.12 \pm 0.44$ & $0.34 \pm 0.18$ \\
\hline $\mathrm{R}^{2} \pm \mathrm{SE} \%$ & $0.34 \pm 78.7$ & $0.44 \pm 74.2$ & $0.13 \pm 350.0$ & $0.21 \pm 47.1$ \\
\hline $\begin{array}{l}\text { F-ratio, } \\
(p \text {-value })\end{array}$ & $\begin{array}{l}6.17 \\
(<0.01)^{*}\end{array}$ & $\begin{array}{l}9.58 \\
(<0.01)^{*}\end{array}$ & $1.71(0.18)$ & $3.23(0.03)^{*}$ \\
\hline $\begin{array}{l}\text { Length }(\beta) \text {, } \\
\text { (p-value) }\end{array}$ & $\begin{array}{l}-0.43 \\
(0.02)^{\star}\end{array}$ & $\begin{array}{l}-0.60 \\
(<0.01)^{*}\end{array}$ & $-0.22(0.29)$ & $-0.41(0.04)^{*}$ \\
\hline $\begin{array}{l}\text { Angle }(\beta), \\
(p \text {-value) }\end{array}$ & $\begin{array}{l}0.76 \\
(<0.01)^{*}\end{array}$ & $-0.14(0.30)$ & $0.21(0.45)$ & $0.23(0.22)$ \\
\hline $\begin{array}{l}\text { Surface Area }(\beta) \text {, } \\
(p \text {-value })\end{array}$ & $-0.07(0.72)$ & $\begin{array}{l}0.42 \\
(<0.01)^{*}\end{array}$ & $0.21(0.36)$ & $-0.23(0.17)$ \\
\hline
\end{tabular}

*Denotes significance. 
520 Table 3. Linear regression model, between predictors and the kinematic

521 variable horizontal launch angle, $R^{2}$ and standardised coefficients with

522 human participants

\begin{tabular}{ccc}
\hline & GEL $^{\circledR}$-Srixon & Odyssey-Srixon \\
\hline Mean \pm SD (Right (+), Left $\left.(-),{ }^{\circ}\right)$ & $-0.07 \pm 1.57$ & $-0.22 \pm 1.50$ \\
$\mathrm{R}^{2} \pm \mathrm{SE}$ & $0.02(1.58)$ & $0.01 \pm 1.50$ \\
F-ratio, $(p$-value) & $0.76(0.52)$ & $0.81(0.49)$ \\
Length ( $\beta),(p$-value) & $-0.04(0.65)$ & $-0.09(0.28)$ \\
Angle ( $\beta),(p$-value) & $-0.12(0.23)$ & $0.03(0.67)$ \\
Surface Area $(\beta),(p$-value) & $0.02(0.88)$ & $-0.04(0.66)$ \\
\hline
\end{tabular}

523

524

525

526

527

528

529

530

531

532

533

534

535

536

537

538

539

540

541 
542 Table 4. Linear regression model, between predictors and the kinematic 543 variable side spin, $\mathrm{R}^{2}$ and standardised coefficients are reported.

\begin{tabular}{|c|c|c|c|c|}
\hline & $\mathrm{GEL}^{\circledR}{ }^{\circledR}$-Titleist & $\begin{array}{l}\mathrm{GEL}^{\circledR}{ }_{-} \\
\text {Srixon }\end{array}$ & $\begin{array}{c}\text { Odyssey- } \\
\text { Titleist }\end{array}$ & $\begin{array}{c}\text { Odyssey- } \\
\text { Srixon }\end{array}$ \\
\hline $\begin{array}{c}\text { Mean } \pm \text { SD } \\
(\text { Cut }(+), \text { Hook } \\
(-), \text { rpm })\end{array}$ & $\begin{array}{c}-12.62 \pm \\
18.35\end{array}$ & $\begin{array}{l}1.64 \pm \\
15.25\end{array}$ & $\begin{array}{c}-13.36 \pm \\
13.76\end{array}$ & $0.86 \pm 14.32$ \\
\hline $\mathrm{R}^{2} \pm \mathrm{SE}$ & $0.20 \pm 16.50$ & $\begin{array}{l}0.17 \pm \\
14.47\end{array}$ & $0.16 \pm 13.16$ & $0.20 \pm 13.31$ \\
\hline $\begin{array}{l}\text { F-ratio, } \\
\text { (p-value) }\end{array}$ & $2.84(0.052)$ & $2.43(0.08)$ & $2.21(0.10)$ & $3.04(0.04)^{*}$ \\
\hline $\begin{array}{l}\text { Length }(\beta) \text {, } \\
\text { (p-value) }\end{array}$ & $-0.31(0.10)$ & $\begin{array}{l}-0.32 \\
(0.07)\end{array}$ & $-0.29(0.16)$ & $-0.02(0.93)$ \\
\hline $\begin{array}{l}\text { Angle }(\beta), \\
(p \text {-value) }\end{array}$ & $-0.26(0.24)$ & $\begin{array}{l}-0.14 \\
(0.39)\end{array}$ & $-0.07(0.79)$ & $-0.37(0.052)$ \\
\hline
\end{tabular}

Surface Area

$(\beta),(p$-value)

$0.10(0.62) \quad 0.27(0.11) \quad-0.13(0.56) \quad-0.16(0.35)$

${ }^{\star}$ Denotes significance.

545

546

547

548

549

550

551

552 
553 Table 5. Linear regression model, between predictors and the kinematic ball 554 roll variable side spin, $\mathrm{R}^{2}$ and standardised coefficients are reported with 555 human participants.

\begin{tabular}{ccc}
\hline & $\mathrm{GEL}^{\circledR}$-Srixon & Odyssey-Srixon \\
\hline Mean \pm SD (Cut $(+)$, Hook $(-)$, rpm) & $-10.90 \pm 25.69$ & $-8.00 \pm 24.87$ \\
$\mathrm{R}^{2} \pm \mathrm{SE}$ & $0.06(20.74)$ & $0.003 \pm 25.04$ \\
F-ratio, $(p$-value) & $2.87(0.04)^{*}$ & $0.15(0.93)$ \\
Length $(\beta),(p$-value $)$ & $-0.10(0.26)$ & $-0.05(0.52)$ \\
Angle $(\beta),(p$-value $)$ & $-0.04(0.69)$ & $-0.002(0.98)$ \\
Surface Area $(\beta),(p$-value $)$ & $0.21(0.03)^{*}$ & $0.007(0.94)$ \\
\hline
\end{tabular}

$556{ }^{*}$ Denotes significance.

557

558 


\section{Figure titles}

560 Figure 1. Examples of the two types of contact possible during impact

561 between the putter face and golf ball. Image A) highlighted area shows the

562 square contact with a dimple and Image B) highlighted area shows the

563 contact where an edge of a dimple is struck.

564

565 Figure 2. Diagram demonstrating the 2D structure identifying the centroid,

566 the polygon used to identify the centre of impact and impact variables; A)

567 length of the impact point from the centroid, B) line representing $90^{\circ}$

568 (normalised to each image) the angle is represented by the degrees between

569 line $A$ and $B$ and the area surrounded by the solid white line was the surface

570 area of the impact zone.

571

572 Figure 3. X, Y scatterplot graphs demonstrating the variability in the impact

573 point, axes have been adjusted for clarity (a large black circle represents the

5740,0 coordinate). Graphs A - D were completed with the mechanical putting

575 arm and E - F were completed with human participants (HP). 
Figure 1
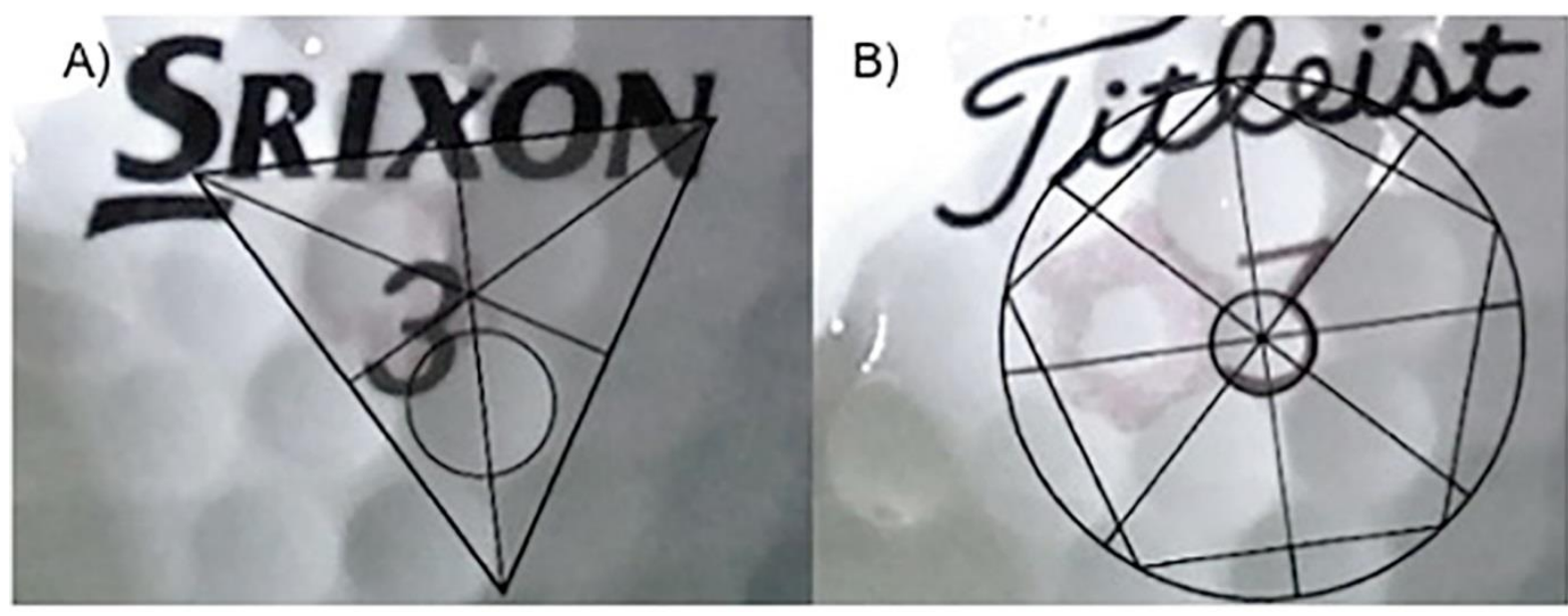

Figure 2

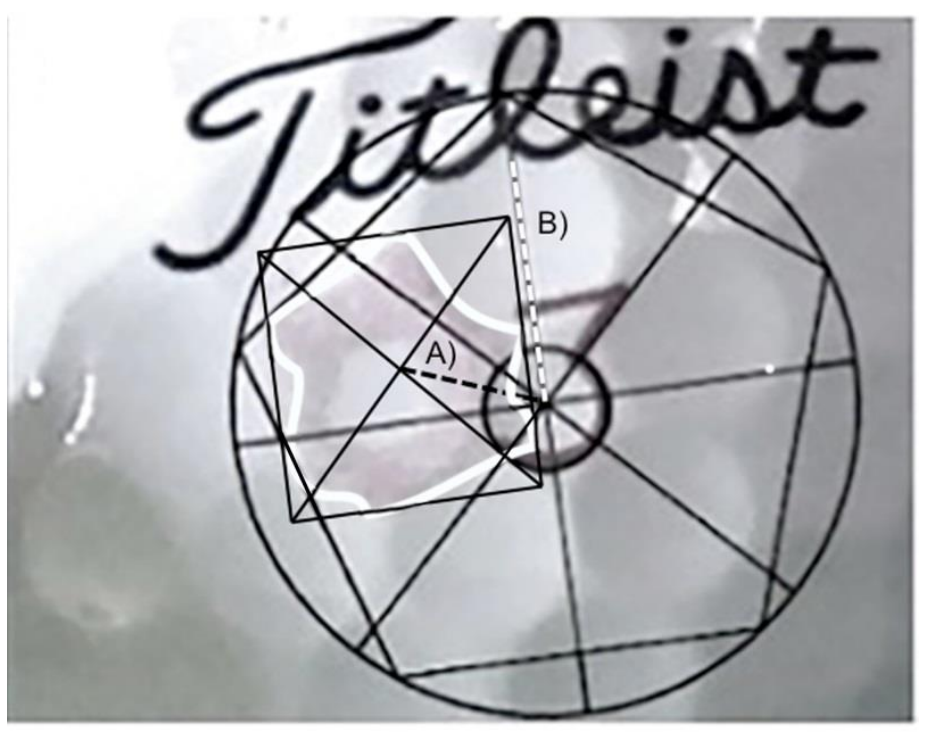


Figure 3
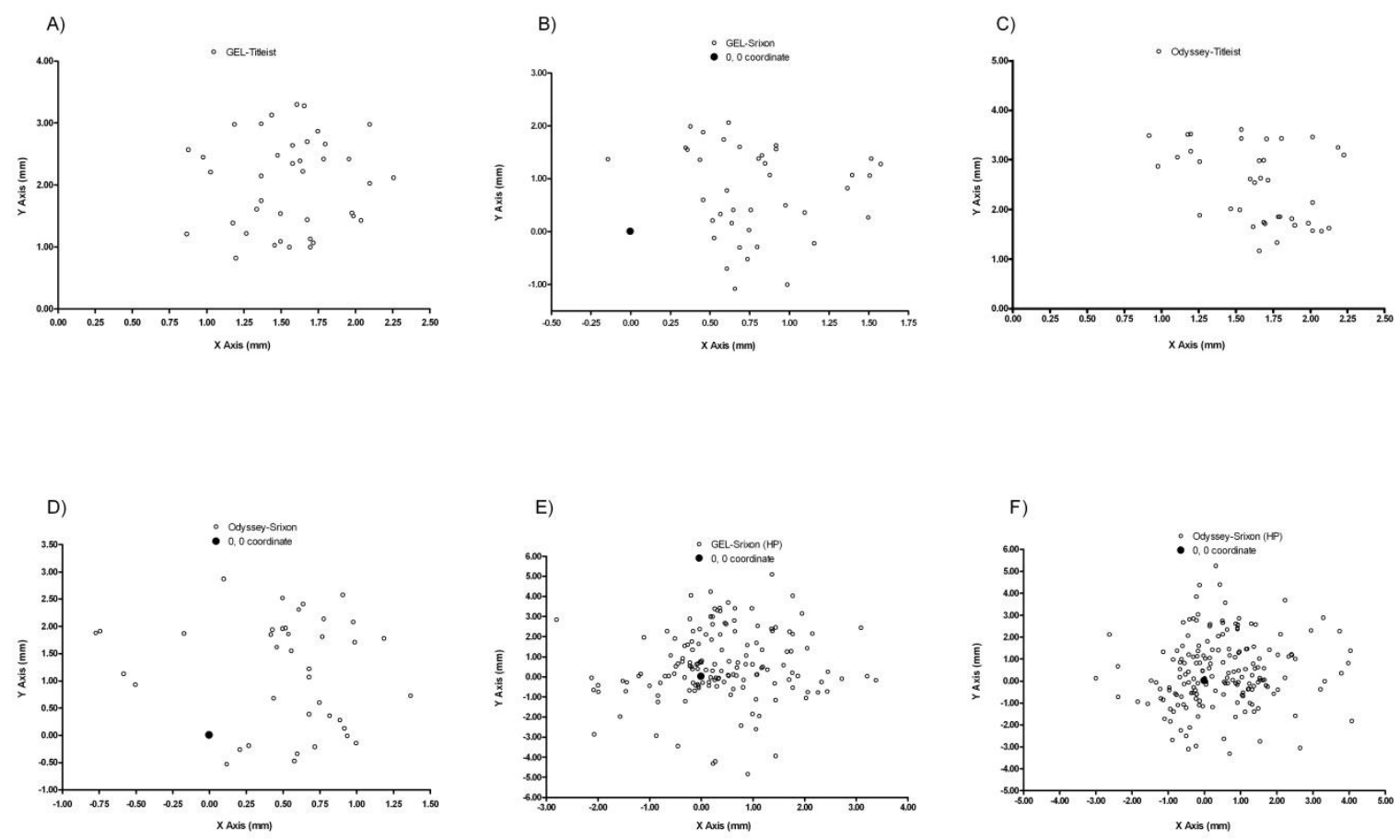